Check for updates

Cite this: RSC Adv., 2017, 7, 50234

\title{
Near-infrared optical performances of two $\mathrm{Bi}_{2} \mathrm{Se}_{3}$ nanosheets $\uparrow$
}

\author{
Hanhan Xie, ${ }^{a}$ Jundong Shao, ${ }^{\mathrm{b}}$ Jiahong Wang, ${ }^{\text {b }}$ Zhengbo Sun, ${ }^{\mathrm{b}}$ Xue-Feng Yu (D) *b \\ and Qu-Quan Wang (iD *a
}

$\mathrm{Bi}_{2} \mathrm{Se}_{3}$ has been widely used as a promising photothermal and photoacoustic agent recently. Herein, twodimensional (2D) $\mathrm{Bi}_{2} \mathrm{Se}_{3}$ nanosheets with different sizes of about $30 \mathrm{~nm}\left(\mathrm{Bi}_{2} \mathrm{Se}_{3}-30\right)$ and $80 \mathrm{~nm}\left(\mathrm{Bi}_{2} \mathrm{Se}_{3}-80\right)$ have been successfully synthesized via solution-based methods. Both of the $\mathrm{Bi}_{2} \mathrm{Se}_{3}$ nanosheets possess high near-infrared (NIR) optical absorption, efficient photothermal conversion and excellent photoacoustic behaviors. Meanwhile, the $\mathrm{Bi}_{2} \mathrm{Se}_{3}-30$ nanosheets perform better. These results indicate the smaller $\mathrm{Bi}_{2} \mathrm{Se}_{3}$ nanosheets are more promising for optical diagnostic and photothermal therapy.

Received 5th September 2017

Accepted 21st October 2017

DOI: $10.1039 / \mathrm{c} 7 \mathrm{ra09872c}$

rsc.li/rsc-advances

research groups including ours have established polyol synthesis

\section{Introduction}

As new quantum matter, topological insulators are one of the most exciting research topics in physics, chemistry and materials fields. ${ }^{1,2}$ In recent years, great efforts have been devoted to theoretical prediction and experimental confirmation of various 2D topological insulators such as $\mathrm{Bi}_{2} \mathrm{Se}_{3}, \mathrm{Bi}_{2} \mathrm{Te}_{3}, \mathrm{Sb}_{2} \mathrm{Te}_{3}$ etc. ${ }^{3-7}$ Among them, $\mathrm{Bi}_{2} \mathrm{Se}_{3}$ invokes a research boom due to its simple band structure near the Dirac point and remarkable band gap..$^{3-5}$ The unique band structure of $\mathrm{Bi}_{2} \mathrm{Se}_{3}$ lead to new electronic and optical properties. ${ }^{89}$ For instance, owing to its graphene-like Dirac energy band structure in its surface state, $\mathrm{Bi}_{2} \mathrm{Se}_{3}$ can operate as a broadband optical material possess remarkable NIR absorption capacity. Furthermore, $\mathrm{Bi}_{2} \mathrm{Se}_{3}$ nanosheets exhibit good bioactivity, biocompatibility, and metabolizability, thus have been proposed as a novel NIR optical nanoagent for bioimaging and therapy applications..$^{10-13}$ Their advantageous 2D structure is also promising for many other biomedical applications such as drug delivery. ${ }^{14}$

It is known that the size of the quantum materials is critically important to their chemical, physical and biological properties. For $2 \mathrm{D} \mathrm{Bi}_{2} \mathrm{Se}_{3}$, the decrease of diameter or thickness can enlarge the energy gap,$^{15}$ enhance the electron-phonon coupling, ${ }^{16}$ and regulate the optical properties. ${ }^{9}$ On the other hand, the size of $\mathrm{Bi}_{2} \mathrm{Se}_{3}$ is also crucial when used as a nanoagent in biomedical applications, which influences not only its cell uptake and biocompatibility, ${ }^{17}$ but also its in vivo clearance. ${ }^{18}$ Recently, many

${ }^{a}$ Department of Physics, Key Laboratory of Artificial Micro- and Nano-structures of Ministry of Education, School of Physics and Technology, Wuhan University, Wuhan 430072, China. E-mail: qqwang@whu.edu.cn

${ }^{b}$ Institute of Biomedicine and Biotechnology, Shenzhen Institutes of Advanced Technology, Chinese Academy of Sciences, Shenzhen 518055, P. R. China. E-mail: xf. yu@siat.ac.cn; jh.wang1@siat.ac.cn

$\dagger$ Electronic supplementary information (ESI) available. See DOI: 10.1039/c7ra09872c strategies to prepare $\mathrm{Bi}_{2} \mathrm{Se}_{3}$ nanosheets and investigate their optical properties. ${ }^{13,19-23}$ However, the size effect on the optical properties of $\mathrm{Bi}_{2} \mathrm{Se}_{3}$ nanosheets has not been reported.

In this study, two $\mathrm{Bi}_{2} \mathrm{Se}_{3}$ nanosheets with well-controlled particle sizes of $30 \mathrm{~nm}$ and $80 \mathrm{~nm}$ are synthesized and their optical absorption properties, NIR photothermal and photoacoustic performances are systematically investigated.

\section{Experimental section}

\subsection{Materials}

The materials used in this study, selenium powders (Se, 99.0\%), acetone $(\geq 99.8 \%)$ and ethylene glycol (EG, $\geq 99.0 \%$ ) were obtained from Sinopharm Chemical Reagent Co. Ltd. (Shanghai, China). Sodium borohydride $\left(\mathrm{NaBH}_{4}, 96.0 \%\right)$, bismuth nitrate pentahydrate $\left(\mathrm{Bi}\left(\mathrm{NO}_{3}\right)_{3} \cdot 5 \mathrm{H}_{2} \mathrm{O}, 99.99+\%\right)$, poly(vinylpyrrolidone) (PVP, $\mathrm{MW} \approx 55000)$, sodium selenite $\left(\mathrm{Na}_{2} \mathrm{SeO}_{3}, 99.0 \%\right)$, and hydroxylamine $\left(\mathrm{NH}_{2} \mathrm{OH}\right)$ were purchased from Sigma-Aldrich. Ultrapure water $\left(18.25 \mathrm{M} \Omega \mathrm{cm}, 25{ }^{\circ} \mathrm{C}\right)$ was used in the experiments.

\subsection{Synthesis of $\mathrm{Bi}_{2} \mathrm{Se}_{3}-30$ nanosheets}

The $\mathrm{Bi}_{2} \mathrm{Se}_{3}-30$ nanosheets were synthesized following our previously reported method. ${ }^{20}$ Firstly, the sodium hydrogen selenium (NaHSe) solution was pre-produced by the reaction of $\mathrm{NaBH}_{4}$ aqueous solution and Se powders in an ice-water bath. Then, $0.5 \mathrm{~g} \mathrm{Bi}\left(\mathrm{NO}_{3}\right)_{3} \cdot 5 \mathrm{H}_{2} \mathrm{O}$ and $0.226 \mathrm{~g}$ PVP were mixed at room temperature in ethylene glycol (EG). The well-mixed transparent solution turned turbid yellow when heated to $160{ }^{\circ} \mathrm{C}$ under a nitrogen environment. The pre-prepared oxygen-free NaHSe solution $\left(0.667 \mathrm{~mol} \mathrm{~L}^{-1}, 1.048 \mathrm{~mL}\right)$ was rapidly injected into the mixture by a syringe. The mixture turned dark immediately, indicating the formation of $\mathrm{Bi}_{2} \mathrm{Se}_{3}-30$ nanosheets. The reaction was continued $10 \mathrm{~min}$ before cooling to room temperature. 


\subsection{Synthesis of $\mathrm{Bi}_{2} \mathrm{Se}_{3}-80$ nanosheets}

The $\mathrm{Bi}_{2} \mathrm{Se}_{3}-80$ nanosheets were synthesized as previously published..$^{19} 1.0 \mathrm{~g}$ PVP was dissolved in $50 \mathrm{~mL}$ EG, then poured into $250 \mathrm{~mL}$ round-bottom flask, followed by the addition of a solution of $\mathrm{Na}_{2} \mathrm{SeO}_{3}(0.242 \mathrm{~g}$ in $35 \mathrm{~mL}$ of $\mathrm{EG})$ and $\mathrm{Bi}\left(\mathrm{NO}_{3}\right)_{3} \cdot 5 \mathrm{H}_{2} \mathrm{O}(0.452 \mathrm{~g}$ in $25 \mathrm{~mL}$ of EG) under magnetic stirring at room temperature. The sealed flask was heated to $160{ }^{\circ} \mathrm{C}$ under a nitrogen environment. The reaction took place by rapid injection of a hydroxylamine solution ( $\mathrm{NH}_{2} \mathrm{OH}, 2.4 \mathrm{~mL}$ in $20 \mathrm{~mL}$ of EG). The reaction mixture turned dark purple immediately, indicating the formation of $\mathrm{Bi}_{2} \mathrm{Se}_{3}-80$ nanosheets. The reaction was continued $10 \mathrm{~min}$ for a complete reaction before cooling to room temperature.

\subsection{Characterizations}

Transmission electron microscopy (TEM) and high-resolution TEM (HR-TEM) images were acquired on the Tecnai G2 F20 STwin transmission electron microscope at an acceleration voltage of $200 \mathrm{kV}$. Powder X-ray diffraction (XRD) patterns were obtained on the D8 Advance (Bruker, Germany) with $\mathrm{Cu} \mathrm{K} \alpha$ radiation $(\lambda=0.1542 \mathrm{~nm})$ at $40 \mathrm{kV}$ and $40 \mathrm{~mA}$. Energy-dispersive $\mathrm{X}$-ray spectrometry (EDS) was performed on the SEM equipped with an Oxford INCA 300. Atomic force microscopy (AFM) images were obtained from the MFP-3D-S atomic force microscope (Asylum Research, USA) using the AC mode (tapping mode) in the air. The UV-vis-NIR extinction spectra were recorded on a Lambda25 spectrophotometer (PerkinElmer) with QS-grade quartz cuvettes at room temperature. The $\mathrm{Bi}_{2} \mathrm{Se}_{3}$ concentrations were measured by an inductively-coupled plasma optical emission spectrometry (ICP-OES, 7000DV, PerkinElmer).

\subsection{NIR photothermal effect measurement}

The NIR photothermal effect was determined with an infrared thermal imaging camera (Fluke Ti27, USA), using the fibercoupled continuous semiconductor diode laser (808 nm, KS810F-8000, Kai Site Electronic Technology Co., Ltd. Shanxi, China) as the irradiation source. All samples were dispersed in ultrapure water with the same absorbance intensities as 0.3 at $808 \mathrm{~nm}$. Subsequently, a $1 \mathrm{~cm}$ path length quartz cuvette containing $1 \mathrm{~mL}$ of the corresponding sample was irradiated by the laser with a power density of $1.0 \mathrm{~W} \mathrm{~cm}^{-2}$ for $12 \mathrm{~min}$. The laser spot was adjusted to cover the entire surface of the sample. The temperature during the heating and cooling periods was recorded one time per $30 \mathrm{~s}$ by the infrared thermal imaging camera.

\subsection{Photoacoustic performance}

The $\mathrm{Bi}_{2} \mathrm{Se}_{3}$ nanosheets aqueous solutions were placed in a hemispherical acrylic holder and suspended in the center of the imaging dimple of the Endra Nexus 128 photoacoustic instrument. The transducers were coupled to the sample plane by filling the bowl with water and maintained at $38{ }^{\circ} \mathrm{C}$ by a pumping system. The photoacoustic signals were obtained at an incident laser wavelength of $808 \mathrm{~nm}$. The photoacoustic signal intensities were acquired by using the ROI in the baseline image and the intensity changes in the ROI of the sample images were calculated.

\section{Results and discussion}

\subsection{Synthesis and characterizations of $\mathrm{Bi}_{2} \mathrm{Se}_{3}$ nanosheets}

The two kinds of $\mathrm{Bi}_{2} \mathrm{Se}_{3}$ nanosheets were synthesized by solution-based methods illustrated in Experimental section. The morphologies of these $\mathrm{Bi}_{2} \mathrm{Se}_{3}$ nanosheets were characterized by TEM and HR-TEM (Fig. 1). The TEM images in Fig. 1a and $b$ reveal the uniform morphologies of these two $\mathrm{Bi}_{2} \mathrm{Se}_{3}$ nanosheets. According to the statistical TEM analysis of 200 nanosheets, the average lateral sizes of the two $\mathrm{Bi}_{2} \mathrm{Se}_{3}$ nanosheets are determined to be approximately $30 \pm 5 \mathrm{~nm}$ (denoted as $\mathrm{Bi}_{2} \mathrm{Se}_{3}-30$ ) and $80 \pm 15 \mathrm{~nm}$ (denoted as $\mathrm{Bi}_{2} \mathrm{Se}_{3}-80$ ), respectively. Different from the smooth surface of the $\mathrm{Bi}_{2} \mathrm{Se}_{3}-30$ nanosheets (Fig. 1c), a screw protrusion is observed in the center of the $\mathrm{Bi}_{2} \mathrm{Se}_{3}-80$ nanosheets (Fig. 1e). The morphological differences may be attributed to the supersaturation of the reaction system. ${ }^{24}$ However, the lattice fringes in Fig. 1d and $\mathrm{f}$ are both ascribed to the (110) plane of $\mathrm{Bi}_{2} \mathrm{Se}_{3}$ as $0.21 \mathrm{~nm}$, which suggest similar crystalline structures between the two $\mathrm{Bi}_{2} \mathrm{Se}_{3}$ nanosheets. ${ }^{13}$ Additionally, the XRD analyses confirm the rhombohedral structure of the two $\mathrm{Bi}_{2} \mathrm{Se}_{3}$ nanosheets (JCPDS card no. 33-0214) (Fig. S1 $\dagger$ ). ${ }^{25}$ The chemical compositions of them were further determined by EDS. It is confirmed that their ratios of Bi to Se both are $2: 3$ (Fig. S2 $\dagger$ ).

The AFM images in Fig. 2 show the 3D topographic morphologies of the $\mathrm{Bi}_{2} \mathrm{Se}_{3}-30$ and $\mathrm{Bi}_{2} \mathrm{Se}_{3}-80$ nanosheets, the corresponding thicknesses are determined by the crosssectional analysis. The average thickness of the $\mathrm{Bi}_{2} \mathrm{Se}_{3}-30$ nanosheets measured in the AFM image is statistically $1.8 \pm$ $0.5 \mathrm{~nm}$ (Fig. 2b), which is as thin as two quintuple atomic layers of $\mathrm{Bi}_{2} \mathrm{Se}_{3}$. Comparatively, the average thickness of the $\mathrm{Bi}_{2} \mathrm{Se}_{3}-80$ nanosheets is $8.3 \pm 1.0 \mathrm{~nm}$ (Fig. 2d), corresponding to a stack of $8 \pm 1$ quintuple layers.

\subsection{Optical absorption properties}

The absorption properties of the two $\mathrm{Bi}_{2} \mathrm{Se}_{3}$ nanosheets are further investigated. As shown in Fig. 3, the aqueous solution of the two $\mathrm{Bi}_{2} \mathrm{Se}_{3}$ nanosheets exhibit obvious absorption ranging

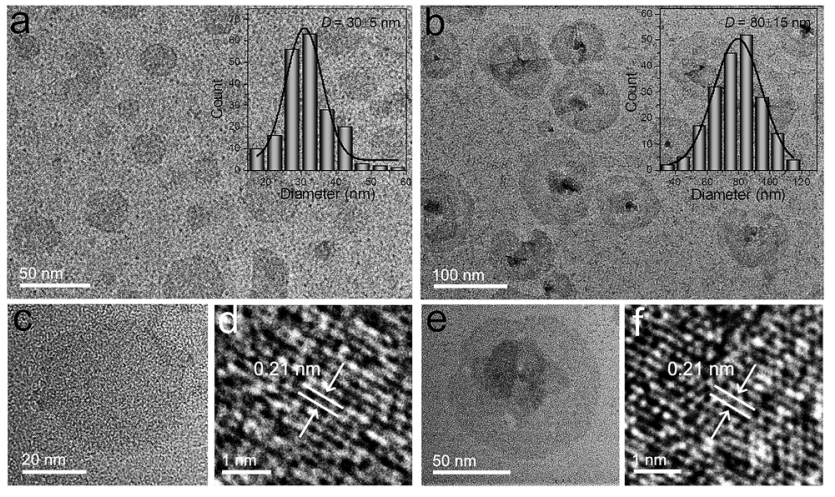

Fig. 1 TEM images of (a) $\mathrm{Bi}_{2} \mathrm{Se}_{3}-30$ and (b) $\mathrm{Bi}_{2} \mathrm{Se}_{3}-80$ nanosheets. Insets: diameter statistical graphs determined from the TEM images; (c) magnified TEM and (d) HR-TEM images of $\mathrm{Bi}_{2} \mathrm{Se}_{3}-30$ nanosheets; (e) magnified TEM and (f) HR-TEM images of $\mathrm{Bi}_{2} \mathrm{Se}_{3}-80$ nanosheets. 

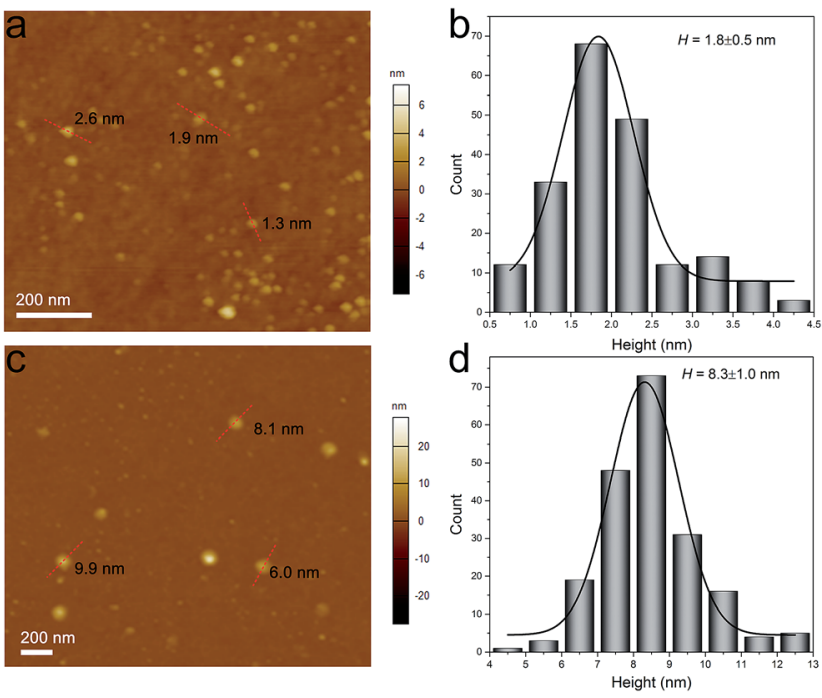

Fig. 2 AFM images and height statistical analysis of $(a, b) \mathrm{Bi}_{2} \mathrm{Se}_{3}-30$ and (c, d) $\mathrm{Bi}_{2} \mathrm{Se}_{3}-80$ nanosheets.

from ultraviolet to NIR, which is similar to other 2D layered materials such as graphene oxide ${ }^{26}$ and black phosphorus. ${ }^{27}$

Since the nanosheets concentrations $(C)$ are measured by ICP-OES, and the extinction intensities against the quartz cell length $(A / L)$ at $\lambda=808 \mathrm{~nm}$ are determined, the corresponding extinction coefficient $\varepsilon$ can be obtained by using Beer's law: $A / L=\varepsilon C$. The extinction coefficients of $\mathrm{Bi}_{2} \mathrm{Se}_{3}-30$ and $\mathrm{Bi}_{2} \mathrm{Se}_{3}-80$ nanosheets at $808 \mathrm{~nm}$ are determined to be 11.3 and 10.7 $\mathrm{L} \mathrm{g}^{-1} \mathrm{~cm}^{-1}$, respectively. Both values are noticeably higher than the common photothermal agent gold nanorods (GNRs) $\left(3.9 \mathrm{~L} \mathrm{~g}^{-1} \mathrm{~cm}^{-1}\right) .{ }^{28}$

The optical band gap $\left(E_{\mathrm{g}}\right)$ of the two $\mathrm{Bi}_{2} \mathrm{Se}_{3}$ nanosheets are also investigated. $E_{\mathrm{g}}$ can be determined by the equation: $(\alpha h v)^{n}$ $=B\left(h v-E_{\mathrm{g}}\right),{ }^{29}$ in which $\alpha$ is the absorption coefficient, $h v$ is photon energy, and $B$ is a constant. Here $n=2$ offers the best fit for the optical absorption data of $\mathrm{Bi}_{2} \mathrm{Se}_{3} \cdot{ }^{29-31}$ The plots of $(\alpha h \nu)^{2}$ versus $h \nu$ for the $\mathrm{Bi}_{2} \mathrm{Se}_{3}$ nanosheets are shown in Fig. S3. $\dagger$ The $E_{\mathrm{g}}$ of the two $\mathrm{Bi}_{2} \mathrm{Se}_{3}$ nanosheets are acquired by extrapolating the straight portion of the plot to intersect the energy axis. The $E_{\mathrm{g}}$ of the $\mathrm{Bi}_{2} \mathrm{Se}_{3}-30$ and $\mathrm{Bi}_{2} \mathrm{Se}_{3}-80$ nanosheets are determined to be 2.14 and $1.99 \mathrm{eV}$, respectively.
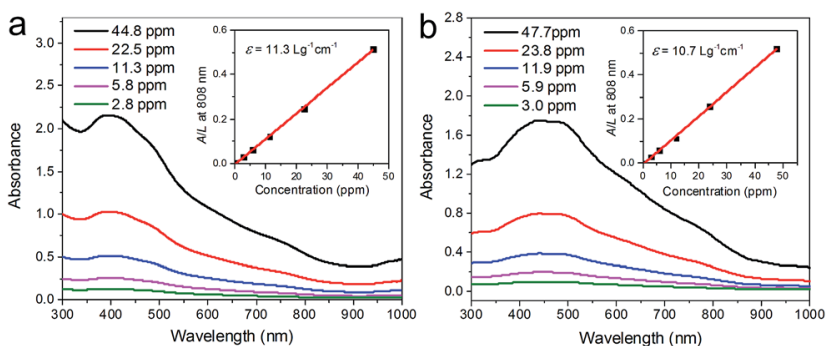

Fig. 3 Absorption spectra of (a) $\mathrm{Bi}_{2} \mathrm{Se}_{3}-30$ and (b) $\mathrm{Bi}_{2} \mathrm{Se}_{3}-80$ nanosheets with various concentrations. Insets: absorbance intensities against the quartz cell length $(A / L)$ with different concentrations $(C)$ at $808 \mathrm{~nm}$.

\subsection{Photothermal performance}

The NIR photothermal performances of the two $\mathrm{Bi}_{2} \mathrm{Se}_{3}$ nanosheets were investigated by dispersing them in water with the same absorbance intensity of 0.30 at $808 \mathrm{~nm}$. Then, the temperatures were measured during the irradiation of an $808 \mathrm{~nm}$ laser at low power density $\left(1.0 \mathrm{~W} \mathrm{~cm}^{-2}\right)$ for $12 \mathrm{~min}$.

The photographs and corresponding infrared thermal images of the solutions are shown in Fig. 4a, and their temperature heating and cooling curves are shown in Fig. $4 \mathrm{~b}$. Compared with pure water, the aqueous solutions of the two $\mathrm{Bi}_{2} \mathrm{Se}_{3}$ nanosheets show much more significant temperature increase. To further uncover the photothermal performance of the two $\mathrm{Bi}_{2} \mathrm{Se}_{3}$ nanosheets, the photothermal conversion efficiency $(\eta)$ is calculated based on the energy balance of the system as shown below: $:^{32-34}$

$$
\begin{gathered}
\eta=\left(h S\left(T_{\max }-T_{\text {surr }}\right)-Q_{\mathrm{dis}}\right) / I\left(1-10^{-A}\right) \\
h S=\sum m C_{\mathrm{p}} / \tau_{\mathrm{s}}
\end{gathered}
$$

Where $h$ is the heat transfer coefficient, $S$ is the surface area of the container, $T_{\max }$ is the maximum temperature at steady-state, $T_{\text {surr }}$ is the surrounding ambient temperature, $I$ is the laser power density $\left(1.0 \mathrm{~W} \mathrm{~cm}^{-2}\right)$, and $A$ is the absorption intensity at $808 \mathrm{~nm}\left(A_{808}=0.3\right) . Q_{\mathrm{dis}}$ is the heat associated with light absorption by the solvent. The variable $\tau_{\mathrm{s}}$ is the time constant for the heat transfer from the system, $m$ and $C_{\mathrm{p}}$ are the mass $(1.0 \mathrm{~g})$ and the specific heat capacity $\left(4.2 \mathrm{~J} \mathrm{~g}^{-1} \mathrm{C}^{-1}\right)$ of the water used as the solvent. According to eqn (1) and (2), the $\eta$ values of the $\mathrm{Bi}_{2} \mathrm{Se}_{3}-30$ and $\mathrm{Bi}_{2} \mathrm{Se}_{3}-80$ nanosheets are calculated to be $33 \%$ and $25 \%$, respectively. The $\eta$ value of the $\mathrm{Bi}_{2} \mathrm{Se}_{3}-30$ nanosheets
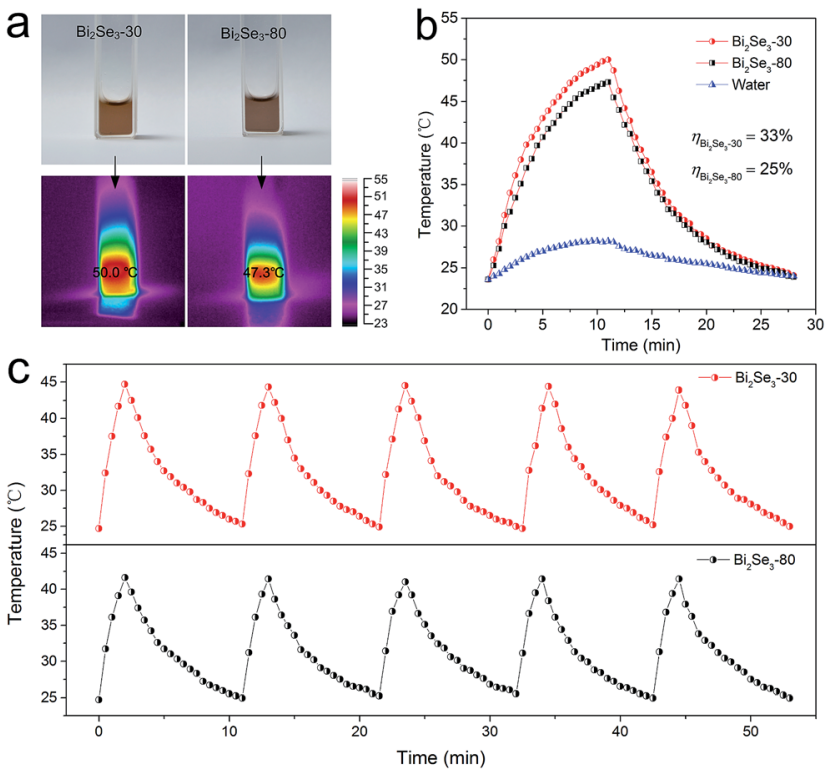

Fig. 4 (a) Photographs (top) and infrared thermal images (down) of the two $\mathrm{Bi}_{2} \mathrm{Se}_{3}$ nanosheets aqueous solution with the same absorption intensities of 0.3 at $808 \mathrm{~nm}$. (b) Photothermal heating/cooling curves of the two $\mathrm{Bi}_{2} \mathrm{Se}_{3}$ nanosheets under $808 \mathrm{~nm}$ laser. (c) Temperature elevation of the two $\mathrm{Bi}_{2} \mathrm{Se}_{3}$ nanosheets for five laser on/off cycles. 
is significantly higher than that of the $\mathrm{Bi}_{2} \mathrm{Se}_{3}-80$ nanosheets. It could be a result of lower scattering introduced by the smaller particles, by which the external light can be efficiently absorbed instead of being scattered..$^{35}$ Additionally, the thinner structure usually performs more violent atomic oscillation, which is beneficial to the photothermal conversion.

To further evaluate the photothermal stability of the two $\mathrm{Bi}_{2} \mathrm{Se}_{3}$ nanosheets, time-dependent heating-cooling cycles under NIR laser were measured with 2 min laser heating and 10 min natural cooling (Fig. 4c). The cycles are repeated for five times and both of the two $\mathrm{Bi}_{2} \mathrm{Se}_{3}$ nanosheets exhibit excellent photostability.

\subsection{Photoacoustic performance}

When nanoparticles absorb external light, their raised temperature will induce a transient thermoelastic expansion, ${ }^{36}$ which could launch ultrasonic waves to form photoacoustic images. ${ }^{37}$ As a result, the photoacoustic signal of the nanoparticles heavily depends on its optical absorption ability and photoacoustic conversion efficiency, which represents the efficiency of the conversion of absorbed optical energy to acoustic waves. ${ }^{38}$ Therefore, with the same optical absorption, the material with higher photoacoustic conversion efficiency is able to perform stronger photoacoustic signal. ${ }^{39}$

Herein, the photoacoustic imaging is carried out to evaluate the photoacoustic conversion efficiency of the two $\mathrm{Bi}_{2} \mathrm{Se}_{3}$ nanosheets. Fig. 5 exhibits the photoacoustic images of the two $\mathrm{Bi}_{2} \mathrm{Se}_{3}$ nanosheets with same absorbance intensities of 0.3 at $808 \mathrm{~nm}$. It is shown that the photoacoustic intensity of the $\mathrm{Bi}_{2} \mathrm{Se}_{3}-30$ nanosheets is 3 times higher than the $\mathrm{Bi}_{2} \mathrm{Se}_{3}-80$ nanosheets. Due to the smaller size of the $\mathrm{Bi}_{2} \mathrm{Se}_{3}-30$ nanosheets, the increased temperature introduces more cavities and further promotes the thermoelastic expansion. Therefore, the more effective photothermal conversion and greater thermal expansion synergistically will result in the higher photoacoustic conversion capability of the $\mathrm{Bi}_{2} \mathrm{Se}_{3}-30$ nanosheets. ${ }^{38}$ Besides, the

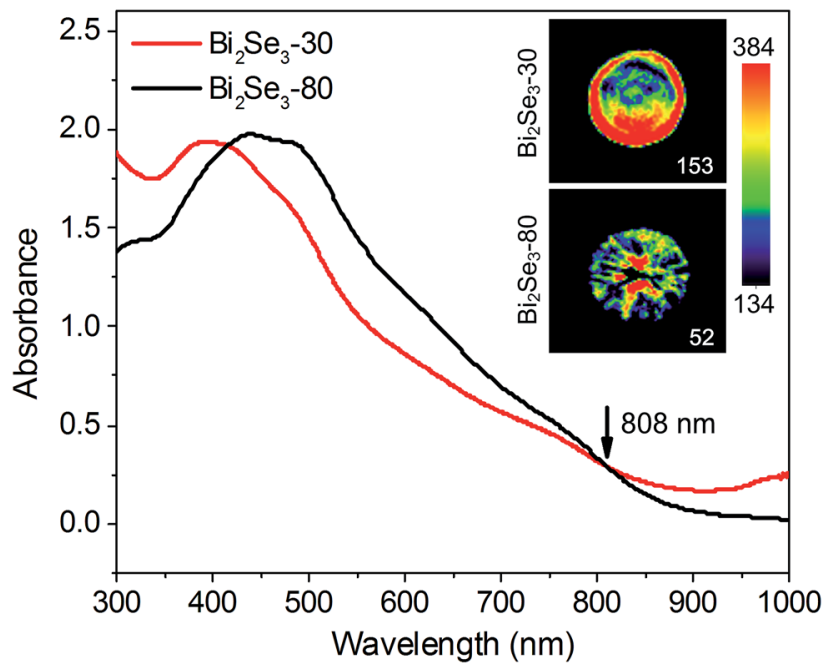

Fig. 5 Photoacoustic images of the two $\mathrm{Bi}_{2} \mathrm{Se}_{3}$ nanosheets with the same absorbance intensities of 0.3 at $808 \mathrm{~nm}$.

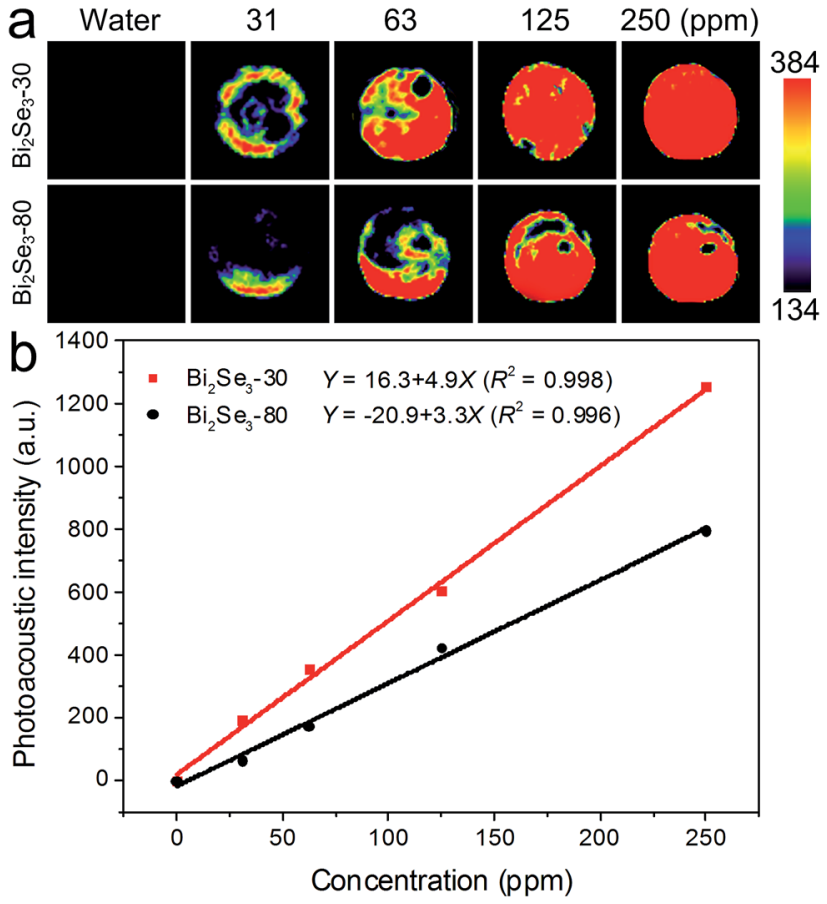

Fig. 6 (a) Photoacoustic images of the two $\mathrm{Bi}_{2} \mathrm{Se}_{3}$ nanosheets aqueous solution with different concentrations. (b) Photoacoustic signal intensities as function of the concentrations.

photoacoustic signal intensities of the two $\mathrm{Bi}_{2} \mathrm{Se}_{3}$ nanosheets are higher than that of GNRs, which is a commonly used photoacoustic agent (Fig. S4†). ${ }^{40}$

Subsequently, the photoacoustic images of the aqueous solutions of the two $\mathrm{Bi}_{2} \mathrm{Se}_{3}$ nanosheets with concentrations from 0 to $250 \mathrm{ppm}$ are illustrated in Fig. 6a. The concentration dependent intensities are described by the equations in Fig. 6 b. The photoacoustic signals are enhanced with the increased $\mathrm{Bi}_{2} \mathrm{Se}_{3}$ concentrations. The $\mathrm{Bi}_{2} \mathrm{Se}_{3}-30$ nanosheets show stronger photoacoustic signal than the $\mathrm{Bi}_{2} \mathrm{Se}_{3}-80$ nanosheets at all concentrations, confirming their better NIR photoacoustic performance.

\section{Conclusions}

In this study, we have successfully prepared two $\mathrm{Bi}_{2} \mathrm{Se}_{3}$ nanosheets $\left(\mathrm{Bi}_{2} \mathrm{Se}_{3}-30\right.$ and $\left.\mathrm{Bi}_{2} \mathrm{Se}_{3}-80\right)$ and characterized them utilizing TEM, HRTEM, XRD, EDS, AFM and UV-vis absorption spectroscopy. The results from optical absorption, NIR photothermal and photoacoustic effect demonstrate that both of the two $\mathrm{Bi}_{2} \mathrm{Se}_{3}$ nanosheets present excellent optical performances. In particular, the optical performances of $\mathrm{Bi}_{2} \mathrm{Se}_{3}-30$ nanosheets with the smaller size are even better. These results indicate that the smaller $\mathrm{Bi}_{2} \mathrm{Se}_{3}$ nanosheets are more promising for optical diagnostic and photothermal therapy.

\section{Conflicts of interest}

There are no conflicts to declare. 


\section{Acknowledgements}

This work was jointly supported by the National Natural Science Fund of China No. 51602204, Leading Talents of Guangdong Province Program (00201520), Guangdong Provincial Scientific Funds (2016A030313055), Program of Public Interest Research and Capability Construction of Guangdong Province (2015A020217010).

\section{Notes and references}

1 J. Moore, Nat. Phys., 2009, 5, 378.

2 D. Kong and Y. Cui, Nat. Chem., 2011, 3, 845.

3 Y. Xia, D. Qian, D. Hsieh, L. Wray, A. Pal, H. Lin, A. Bansil, D. Grauer, Y. S. Hor, R. J. Cava and M. Z. Hasan, Nat. Phys., 2009, 5, 398.

4 H. Peng, K. Lai, D. Kong, S. Meister, Y. Chen, X. Qi, S. Zhang, Z. Shen and Y. Cui, Nat. Mater., 2010, 9, 225.

5 H. Zhang, C. X. Liu, X. L. Qi, X. Dai, Z. Fang and S. C. Zhang, Nat. Phys., 2009, 5, 438.

6 Y. Min, J. W. Roh, H. Yang, M. Park, S. Kim, S. Hwang, S. M. Lee, K. H. Lee and U. Jeong, Adv. Mater., 2013, 25, 1425.

7 Y. L. Chen, J. G. Analytis, J. H. Chu, Z. K. Liu, S.-K. Mo, X. L. Qi, H. J. Zhang, D. H. Lu, X. Dai, Z. Fang, S. C. Zhang, I. R. Fisher, Z. Hussain and Z.-X. Shen, Science, 2009, 325, 178.

8 K. Kadel, L. Kumari, W. Z. Li, J. Y. Huang and P. P. Provencio, Nanoscale Res. Lett., 2011, 6, 57.

9 L. Sun, Z. Lin, J. Peng, J. Weng, Y. Huang and Z. Luo, Sci. Rep., 2014, 4, 4794.

10 L. Cheng, S. Shen, S. Shi, Y. Yi, X. Wang, G. Song, K. Yang, G. Liu, T. E. Barnhart, W. Cai and Z. Liu, Adv. Funct. Mater., 2016, 26, 2185.

11 J. Li, F. Jiang, B. Yang, X. R. Song, Y. Liu, H. H. Yang, D. R. Cao, W. R. Shi and G. N. Chen, Sci. Rep., 2013, 3, 1998. 12 Z. Li, Y. Hu, K. A. Howard, T. Jiang, X. Fan, Z. Miao, Y. Sun, F. Besenbacher and M. Yu, ACS Nano, 2016, 10, 984.

13 X. D. Zhang, J. Chen, Y. Min, G. B. Park, X. Shen, S. S. Song, Y. M. Sun, H. Wang, W. Long, J. Xie, K. Gao, L. Zhang, S. Fan, F. Fan and U. Jeong, Adv. Funct. Mater., 2014, 24, 1718.

14 B. L. Li, M. I. Setyawati, L. Chen, J. Xie, K. Ariga, C. T. Lim, S. Garaj and D. T. Leong, ACS Appl. Mater. Interfaces, 2017, 9, 15286.

15 Y. Zhang, K. He, C. Z. Chang, C. L. Song, L. L. Wang, X. Chen, J. F. Jia, Z. Fang, X. Dai, W. Y. Shan, S. Q. Shen, Q. Niu, X. L. Qi, S. C. Zhang, X. C. Ma and Q. K. Xue, Nat. Phys., 2010, 6, 584.

16 J. Zhang, Z. Peng, A. Son, Y. Zhao, Y. Xiong, B. Peng, J. Wang, M. S. Dresselhaus and Q. Xiong, Nano Lett., 2011, 11, 2407.

17 Z. Li, S. Tang, B. Wang, Y. Li, H. Huang, H. Wang, P. Li, C. Li, P. K. Chu and X. F. Yu, ACS Biomater. Sci. Eng., 2016, 2, 789.
18 C. H. J. Choia, J. E. Zuckermana, P. Websterb and M. E. Davisa, Proc. Natl. Acad. Sci. U. S. A., 2011, 108, 6656.

19 Y. Min, G. D. Moon, B. S. Kim, B. Lim, J. S. Kim, C. Y. Kang and U. Jeong, J. Am. Chem. Soc., 2012, 134, 2872.

20 H. Xie, Z. Li, Z. Sun, J. Shao, X. F. Yu, Z. Guo, J. Wang, Q. Xiao, H. Wang, Q. Q. Wang, H. Zhang and P. K. Chu, Small, 2016, 12, 4136.

21 Z. Li, J. Shao, Q. Luo, X. F. Yu, H. Xie, H. Fu, S. Tang, H. Wang, G. Han and P. K. Chu, Biomaterials, 2017, 133, 37.

22 A. Zhuang, J. J. Li, Y. C. Wang, X. Wen, Y. Lin, B. Xiang, X. Wang and J. Zeng, Angew. Chem., 2014, 126, 6543.

23 S. Cho, N. P. Butch, J. Paglione and M. S. Fuhrer, Nano Lett., 2011, 11, 1925.

24 X. Liu, J. Xu, Z. Fang, L. Lin, Y. Qian, Y. Wang, C. Ye, C. Ma and J. Zeng, Nano Res., 2015, 8, 3612.

25 Z. Sun, S. Liufu, X. Chen and L. Chen, Chem. Commun., 2010, 46, 3101.

26 J. T. Robinson, S. M. Tabakman, Y. Liang, H. Wang, H. S. Casalongue, D. Vinh and H. Dai, J. Am. Chem. Soc., 2011, 133, 6825.

27 Y. Yi, X. F. Yu, W. Zhou, J. Wang and P. K. Chu, Mater. Sci. Eng., $R, 2017,120,1$.

28 Z. Sun, H. Xie, S. Tang, X. F. Yu, Z. Guo, J. Shao, H. Zhang, H. Huang, H. Wang and P. K. Chu, Angew. Chem., 2015, 127, 11688.

29 L. Sun, Z. Lin, J. Peng, J. Weng, Y. Huang and Z. Luo, Sci. Rep., 2014, 4, 4794.

30 X. Yang, X. Wang and Z. Zhang, J. Cryst. Growth, 2005, 276, 566.

31 S. Subramanian and P. Padiyan, Mater. Chem. Phys., 2008, 107, 392.

32 Q. Tian, F. Jiang, R. Zou, Q. Liu, Z. Chen, M. Zhu, S. Yang, J. Wang, J. Wang and J. Hu, ACS Nano, 2011, 5, 9761.

33 J. Cui, R. Jiang, S. Xu, G. Hu and L. Wang, Small, 2015, 11, 4183.

34 P. Huang, J. Lin, W. Li, P. Rong, Z. Wang, S. Wang, X. Wang, X. Sun, M. Aronova, G. Niu, R. D. Leapman, Z. Nie and X. Chen, Angew. Chem., 2013, 125, 14208.

35 C. M. Hessel, V. P. Pattani, M. Rasch, M. G. Panthani, B. Koo, J. W. Tunnell and B. A. Korgel, Nano Lett., 2011, 11, 2560.

36 L. Cavigli, M. Angelis, F. Ratto, P. Matteini, F. Rossi, S. Centi, F. Fusi and R. Pini, J. Phys. Chem. C, 2014, 118, 16140.

37 L. V. Wang and S. Hu, Science, 2012, 335, 1458.

38 Y. Shi, H. Qin, S. Yang and D. Xing, Nano Res., 2016, 9, 3644. 39 Y. S. Chen, W. Frey, S. Kim, P. Kruizinga, K. Homan and S. Emelianov, Nano Lett., 2011, 11, 348.

40 E. C. Cho, C. Kim, F. Zhou, C. M. Cobley, K. H. Song, J. Chen, Z. Y. Li, L. V. Wang and Y. Xia, J. Phys. Chem. C, 2009, 113, 9023. 